\title{
Review of Changes in Amount of Hospitalizations Related to Poisoning by Chosen Psychotropic Drugs (T43 ICD-10) in Lower Silesia Region of Poland in Years 2006-2012
}

\author{
Robert Suslo $^{1}$, Piotr Hanczyc ${ }^{2}$, Jaroslaw Drobnik ${ }^{1}$ \\ ${ }^{1}$ Public Health Department, University Clinical Hospital, Wroclaw, Poland \\ ${ }^{2}$ Obstetrics and Gynecology Department, Wroclaw Medical University, Wroclaw, Poland \\ robertsuslo@gmail.com
}

\begin{abstract}
Poisonings by psychotropic drugs in various manners pose a serious public health, forensic and clinical medicine problem - especially for the medical staff of toxicology, intensive care and anesthesiology wards. Data on hospital admissions secondary to poisonings by chosen psychotropic drugs (T43 according to ICD-10) in the years 2006-2012, made available due to courtesy of the public healthcare insurance provider Narodowy Fundusz Zdrowia in Lower Silesia region of Poland (NFZ), were analyzed in order to find out the current incidence and trends in the most common and important poisonings to facilitate the process of differential diagnosis for both clinical and forensic medicine purposes. The study revealed that the most commonly reported psychotropic drugs intoxications demanding hospitalization were caused by antidepressants - especially tricyclic, tetracyclic and unspecified. The amount of hospital admissions increased in case of poisonings by psychotropic drugs reported without any further active substance specification, as well as due to intoxications caused specifically by: antidepressants other than tricyclic, tetracyclic and monoamine-oxidaseinhibitors; and neuroleptics. There was decrease in hospitalizations due to poisonings by: monoamine-oxidaseinhibitor antidepressants; phenothiazine antipsychotics and neuroleptics; and psychotropic drugs other than antidepressants, antipsychotics, antineuroleptics and psychostimulants. Those findings mirror shifts in medical treatment strategies - from classic drugs into their newly developed alternatives - and the resultant changes in availability of those drugs to general population. The significant amount of cases reported as poisoning by unspecified psychotropic drug confirms difficulties in establishing proper intoxication diagnosis despite the rapid progress in analytic chemistry techniques in the last decades.
\end{abstract}

Keywords: Toxicology; poisoning; psychotropic drugs; antidepressants; antipsychotics; neuroleptics; psychostimulants; forensic medicine

Abbreviations: NFZ - Narodowy Fundusz Zdrowia in Lower Silesia region of Poland, District Division in Wroclaw

\section{INTRODUCTION}

The psychotropic drugs vary significantly in toxicity: the acute toxicity is characteristic for antidepressants, lower in neuroleptics and very low in anxiolytics; the chronic toxicity is highest in neuroleptics while the antidepressants and anxiolytics prove to be less harmful; additionally antidepressants have a low therapeutic index and it results in numerous fatal poisonings of different manner [1]. Therapeutic psychotropic drugs prove to be an important cause of accidental poisonings in children [2]. Nevertheless, around $90 \%$ of deliberate self-harm cases resulting in hospital admission involve deliberate self-poisoning [3]. The amount of cases of deliberate psychotropic drugs selfpoisonings, especially ending in death, is reported to be low in comparison to the high total number of patients who receive those drugs - approximately 3 per 1000 during 1 year of observation - and declines slightly with the patients' age [4]. In case of fatal outcome psychotropic drug poisoning often turns out being multiple psychotropic substances intoxication [5], additionally coexisting with ethanol abuse [6]. Poisonings, including psychotropic drugs, belong to the most popular methods of committing suicide: they occupy the first place in women and are second popular method of taking own life among men [7]. The actual involvement of psychotropic drugs differs from country to country, in some, like Japan, they are the most often overdosed ones - but it generally is a major health problem [8]. Patients with current prescription for psychotropic drugs are more likely to use them in a suicide attempt, especially if they were also prescribed a minor tranquilizer [9]. 
In the Lower Silesia region of Poland there was significant decline in the recent years in the amount of hospital admissions due to poisoning by sedative-hypnotic drugs [10]; also the amount of patients diagnosed with psychiatric disorders in public ambulatory psychiatric health centers dropped in the recent years but the odds are that there is a black number of patients using services of psychiatric private offices that are falling out the main statistics; the most common diagnoses that were established in $80 \%$ of all patients, were: neurotic disorders, organic mental disorders, mood disorders, schizophrenia and schizotypal and delusional disorders - so the demand for psychotropic drugs in the population remains still high [11]. Warnings in the media about a possible increased risk of suicide among antidepressant users result in the past in: decrease in the dispensings amount of these drugs in all age groups, especially among adolescents; increase in poisonings among adolescents; but they did not influence the amount of completed suicides [12]. The psychotropic substances prescriptions shall be given to patients by physicians responsibly and registered meticulously to prevent overmedication and limit drugs abuse [13]. The psychotropic substances intoxications are an important problem both to clinical and forensic medicine and toxicology - and even using advanced analytic chemistry methods does not guarantee positive identification of the initially unknown xenobiotic [14].

\section{Materials AND Methods}

Data on hospital admissions secondary to poisonings by chosen psychotropic drugs (T43 according to ICD-10) in the years 2006-2012, made available due to courtesy of the public healthcare insurance provider Narodowy Fundusz Zdrowia in Lower Silesia region of Poland (NFZ), were analyzed; the data included all admissions to hospital regardless of the subsequent hospital stay duration length. The aim of the study was to find out the current incidence and trends in the most common and important poisonings by chosen psychotropic drugs in the analyzed period of time to facilitate the process of diagnostics for both clinical and forensic medicine purposes.

\section{RESULTS AND DISCUSSION}

In the years 2006-2012 there were no significant changes observed in the Lower Silesia region of Poland population's important characteristics, like its amount or age structure, despite the trend towards population ageing [15]. In the year 2014 there were 2,9 million people living in the Lower Silesia region, $52 \%$ of them were females [16].

The yearly amount of admissions to hospitals in the Lower Silesia region of Poland due to poisoning by psychotropic drugs that are not classified elsewhere, with the exception of: appetite depressants, barbiturates, benzodiazepines, methaqualone and psychodysleptics (T43 according to ICD-10), rose in the years 2006-2012 by 40,8\% of its initial amount; the most dramatic increase was reported in the year 2008 and later the amount of hospitalizations alternated only slightly - as it is visible in Figure 1.

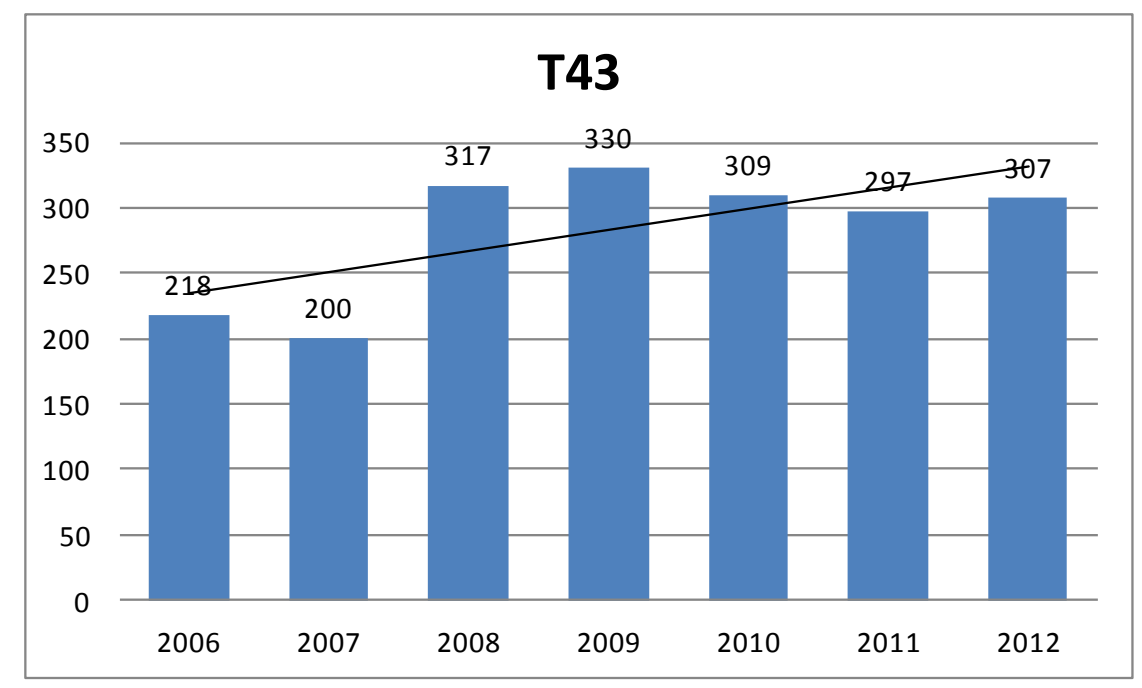

Figure1. Yearly amounts of admissions to hospitals in the Lower Silesia region of Poland in the years 20062012 due to poisoning by psychotropic drugs that are not classified elsewhere, with the exception of: appetite depressants, barbiturates, benzodiazepines, methaqualone and psychodysleptics (T43 according to ICD-10) not specified further; source: data made available by courtesy of the NFZ. 
Review of Changes in Amount of Hospitalizations Related to Poisoning by Chosen Psychotropic Drugs (T43 ICD-10) in Lower Silesia Region of Poland in Years 2006-2012

Poisonings by tricyclic and tetracyclic antidepressants (T43.0 according to ICD-10) were causing hospitalizations in the Lower Silesia region of Poland less and less often - their amount showed the consistent falling trend in the years 2006-2012 and dropped to 67,5\% of its initial value - as it is illustrated in Figure 2. It shall be interpreted at least partially as the result of growing in Poland popularity of alternative drugs to tricyclic and tetracyclic antidepressants.

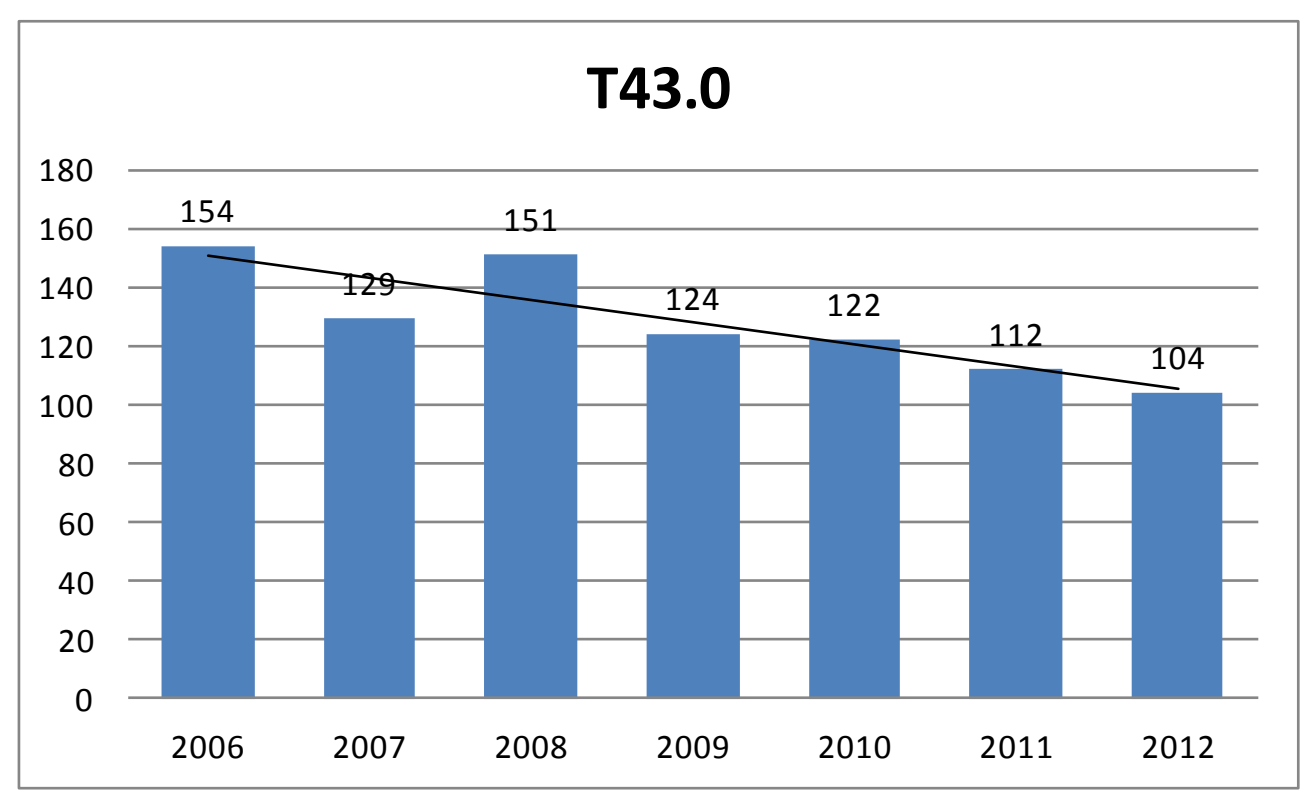

Figure2. Yearly amounts of admissions to hospitals in the Lower Silesia region of Poland in the years 20062012 due to poisoning by tricyclic and tetracyclic antidepressants (T43.0 according to ICD-10); source: data made available by courtesy of the NFZ.

Monoamine-oxidase-inhibitor antidepressants (T43.1 according to ICD-10) poisoning cases requiring hospital admissions were scarce and showed in the years 2006-2012 a decreasing trend - as it is demonstrated in Figure 3.

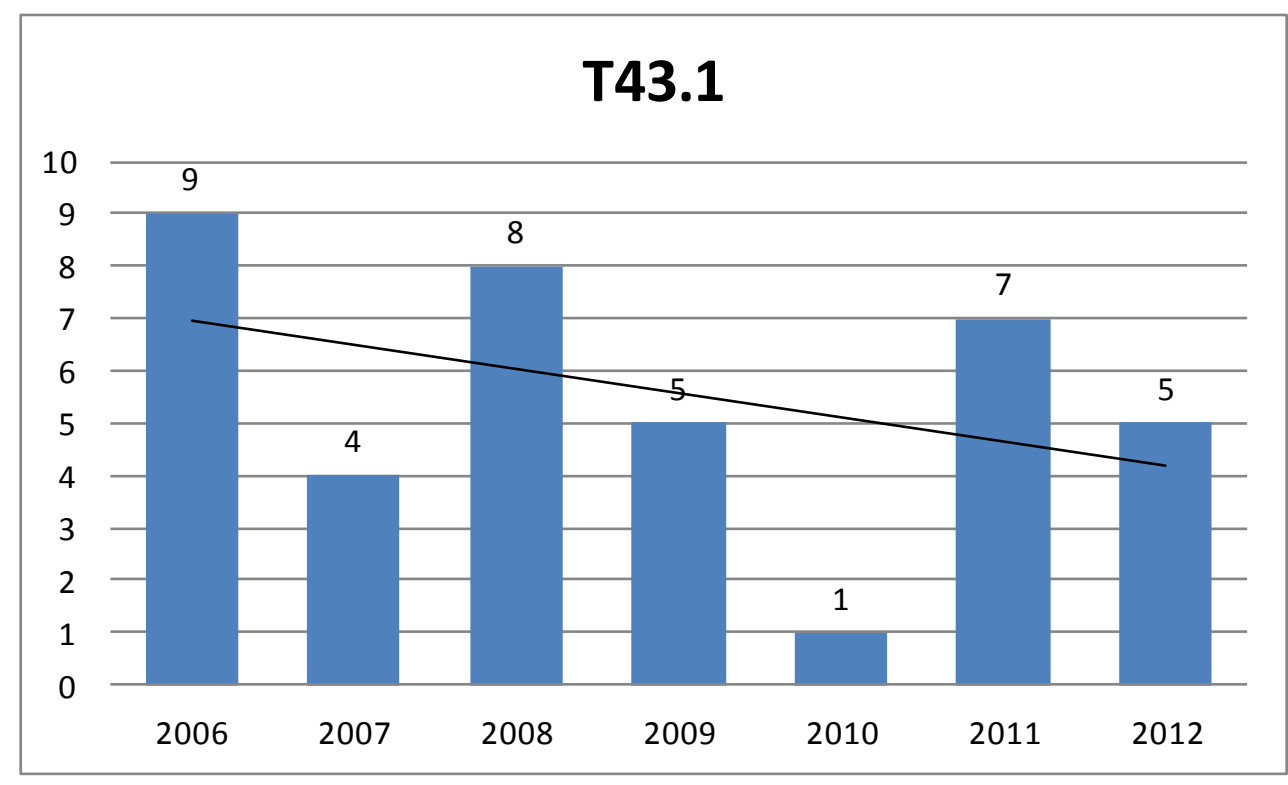

Figure3. Yearly amounts of admissions to hospitals in the Lower Silesia region of Poland in the years 20062012 due to poisoning by monoamine-oxidase-inhibitor antidepressants (T43.1 according to ICD-10); source: data made available by courtesy of the NFZ.

Poisonings by antidepressants other than tricyclic, tetracyclic and monoamine-oxidase-inhibitors, and unspecified antidepressants (T43.2 according to ICD-10) increased in the years 2006-2012 in the Lower Silesia region of Poland by $43 \%$ of the initial amount, with a rapid shift up in the year 2008 - as it is shown in Figure 4. It shall be interpreted as the mirror phenomenon to the dropping incidence of tricyclic and tetracyclic antidepressants poisonings. 


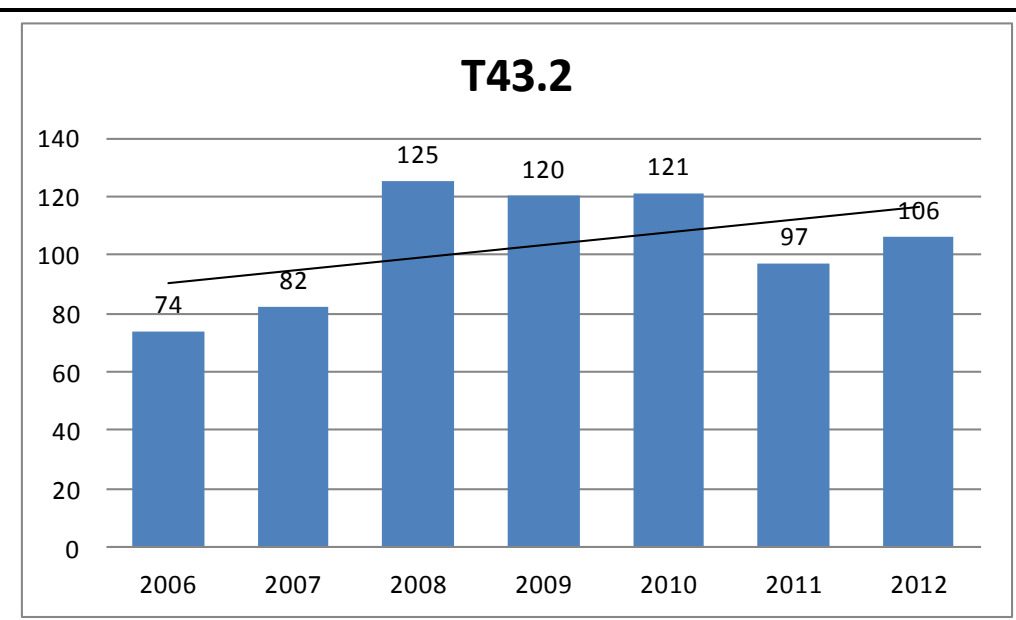

Figure4. Yearly amounts of admissions to hospitals in the Lower Silesia region of Poland in the years 20062012 due to poisoning by antidepressants other than tricyclic, tetracyclic and monoamine-oxidase-inhibitors, and unspecified antidepressants (T43.2 according to ICD-10); source: data made available by courtesy of the NFZ.

The yearly amount of hospital admissions resulting from poisonings by phenothiazine antipsychotics and neuroleptics (T43.3 according to ICD-10) showed the consistent decreasing trend, dropping to $45,4 \%$ of its initial value - as it is demonstrated in Figure 5.

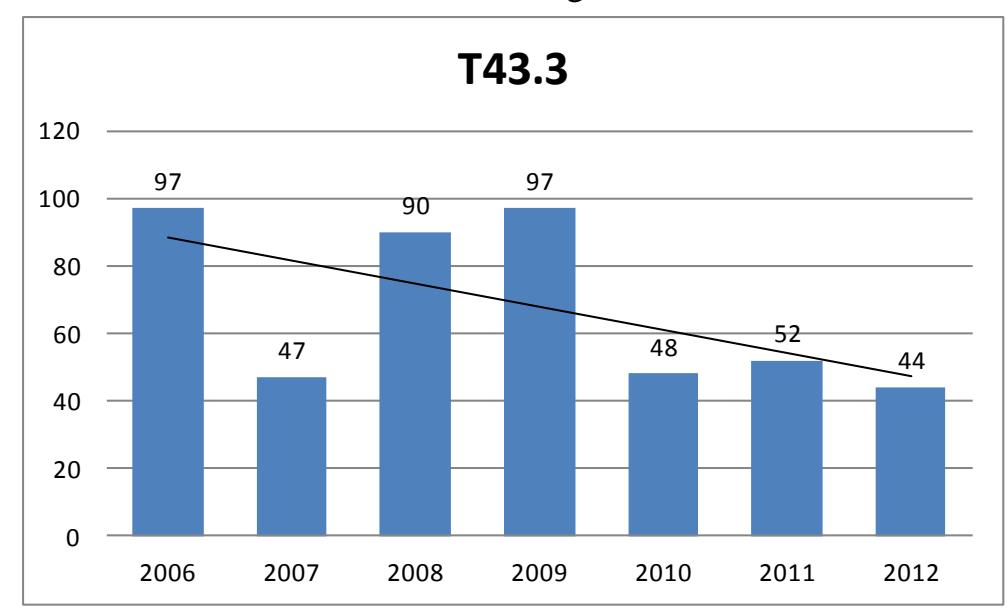

Figure5. Yearly amounts of admissions to hospitals in the Lower Silesia region of Poland in the years 20062012 due to poisoning by phenothiazine antipsychotics and neuroleptics (T43.3 according to ICD-10); source: data made available by courtesy of the NFZ.

The yearly hospitalizations amounts due to poisoning by butyrophenone and thioxanthene neuroleptics (T43.4 according to ICD-10) were alternating in the analyzed period, showing a slightly increasing trend - as it is illustrated in Figure 6.

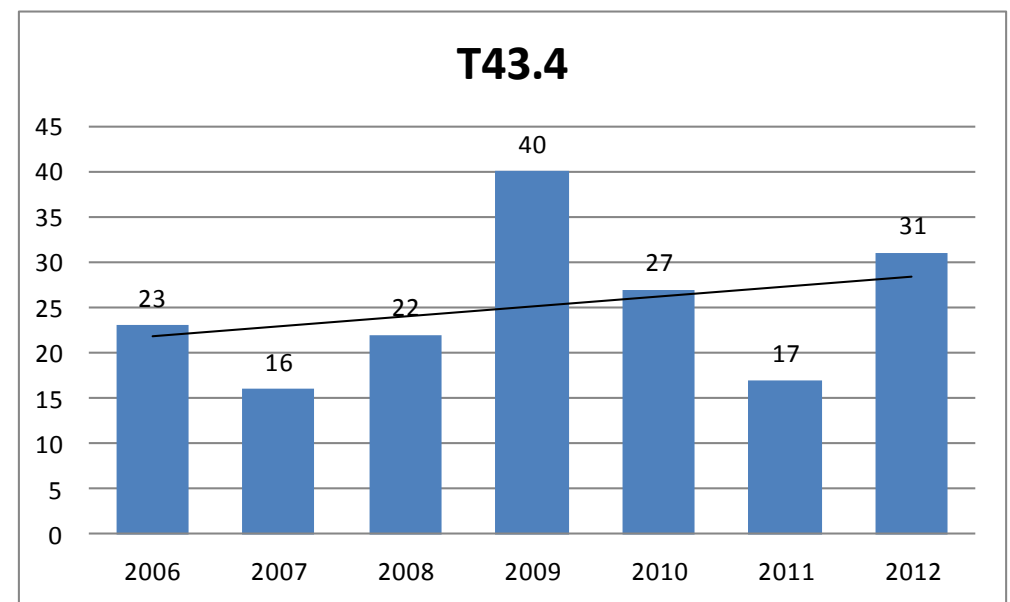

Figure6. Yearly amounts of admissions to hospitals in the Lower Silesia region of Poland in the years 20062012 due to poisoning by butyrophenone and thioxanthene neuroleptics (T43.4 according to ICD-10); source: data made available by courtesy of the NFZ. 
Review of Changes in Amount of Hospitalizations Related to Poisoning by Chosen Psychotropic Drugs (T43 ICD-10) in Lower Silesia Region of Poland in Years 2006-2012

The amount of ending in hospital admission cases of poisoning by antipsychotics and neuroleptics other than butyrophenonone and thioxanthene, and unspecified antipsychotics and neuroleptics, with the exception of rauwolfia (T43.5 according to ICD-10) increased in the years $2006-2012$ by $66,1 \%$ of the initial amount - as it is shown in Figure 7.

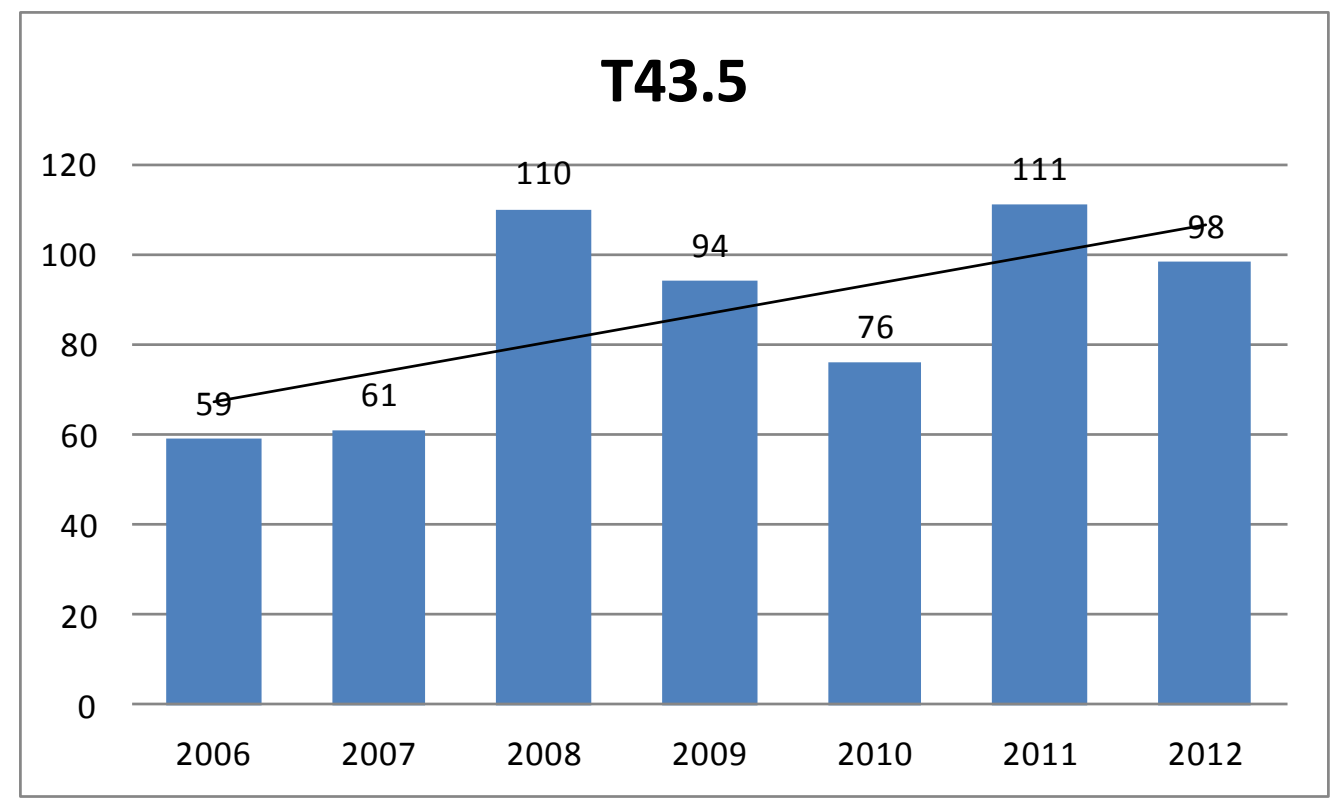

Figure7. Yearly amounts of admissions to hospitals in the Lower Silesia region of Poland in the years 20062012 due to poisoning by antipsychotics and neuroleptics other than butyrophenonone and thioxanthene, and unspecified antipsychotics and neuroleptics, with the exception of rauwolfia (T43.5 according to ICD-10); source: data made available by courtesy of the NFZ.

The amounts of needing hospitalization cases of poisoning by psychostimulants with abuse potential, with the exception of cocaine (T43.6 according to ICD-10) were alternating from year to year in the analyzed time period, without any recognizable trend - as it is demonstrated in Figure 8.

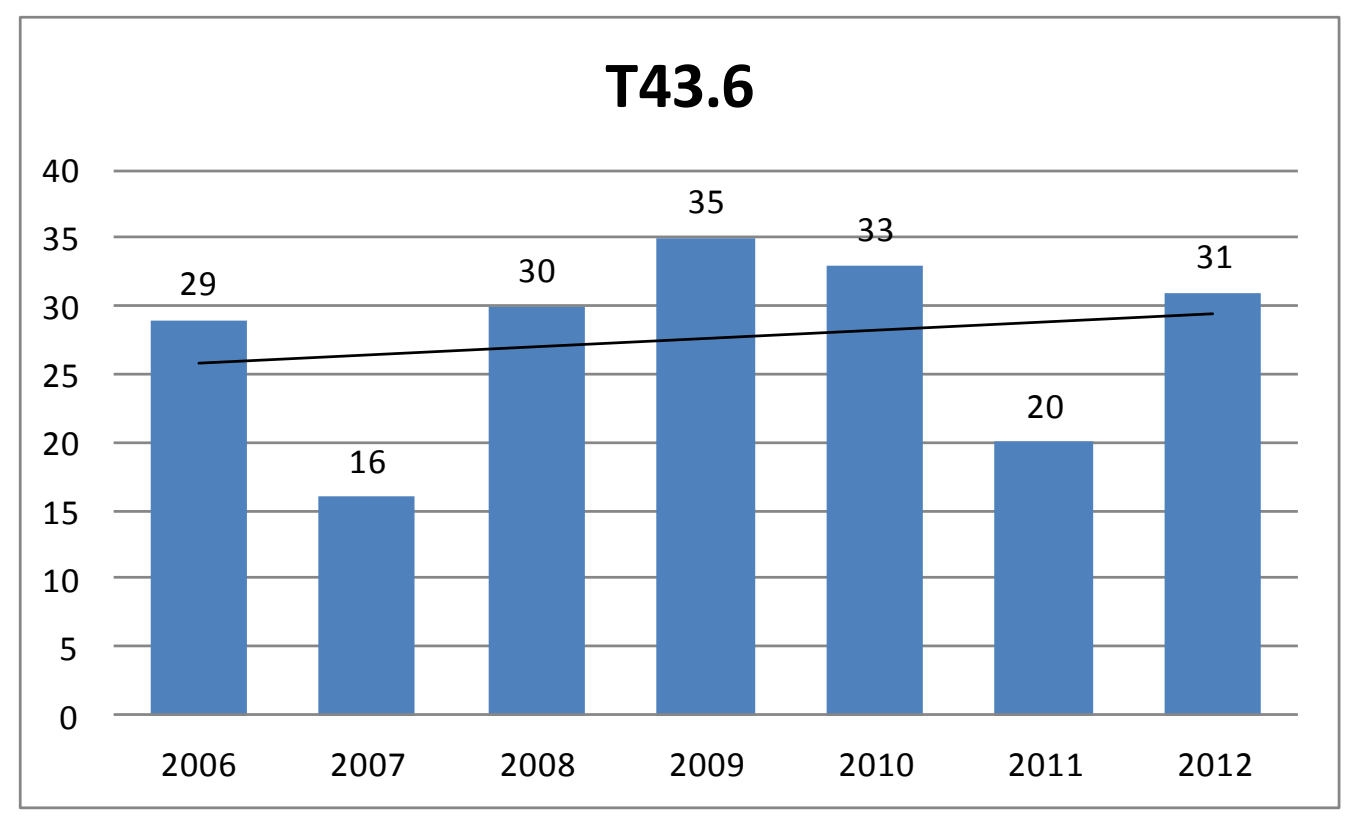

Figure8. Yearly amounts of admissions to hospitals in the Lower Silesia region of Poland in the years 20062012 due to poisoning by psychostimulants with abuse potential, with the exception of cocaine (T43.6 according to ICD-10); source: data made available by courtesy of the NFZ.

The admissions to hospitals in the Lower Silesia region of Poland in the years 2006-2012 due to poisoning by psychotropic drugs other than antidepressants, antipsychotics, antineurolepics and psychostimulants, not classified elsewhere (T43.8 according to ICD-10) showed decreasing trend and dropped to $57,1 \%$ of their initial amount - as it is illustrated in Figure 9. 


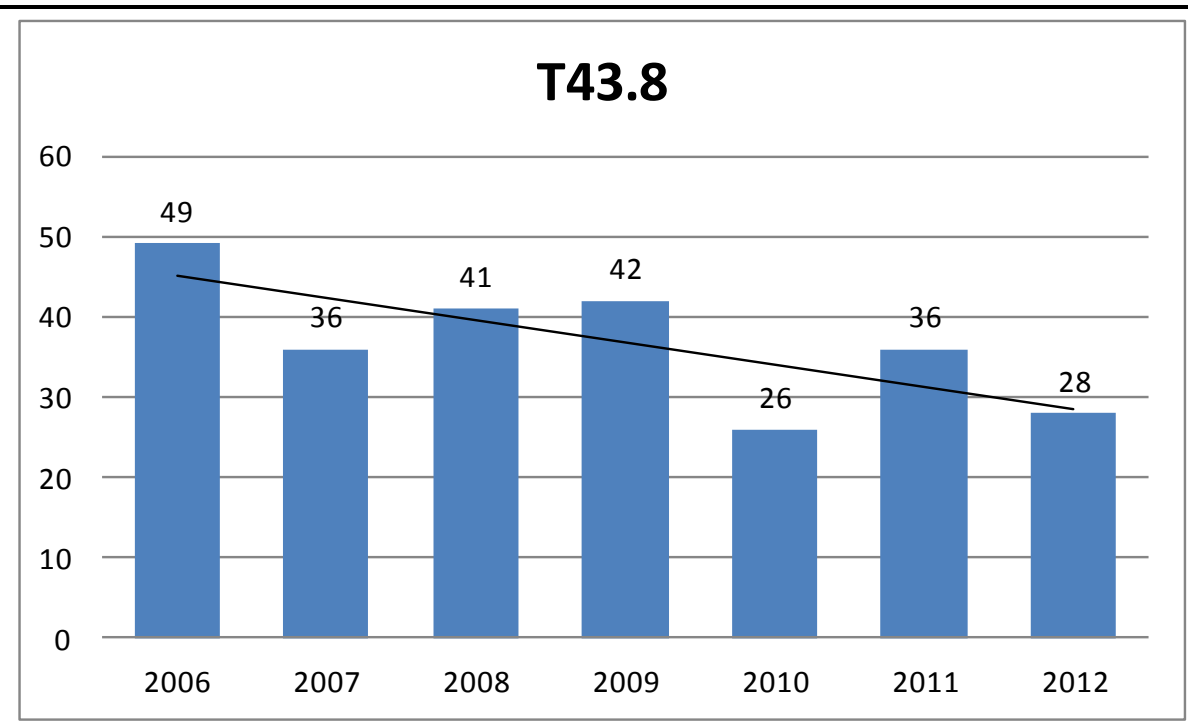

Figure9. Yearly amounts of admissions to hospitals in the Lower Silesia region of Poland in the years 20062012 due to poisoning by psychotropic drugs other than antidepressants, antipsychotics, antineurolepics and psychostimulants, not classified elsewhere (T43.8 according to ICD-10); source: data made available by courtesy of the NFZ.

The reported yearly amounts of intoxications by unspecified psychotropic drugs needing hospital treatment were alternating from year to year in the analyzed time period, showing a slightly decreasing trend - as it is visible in Figure 10.

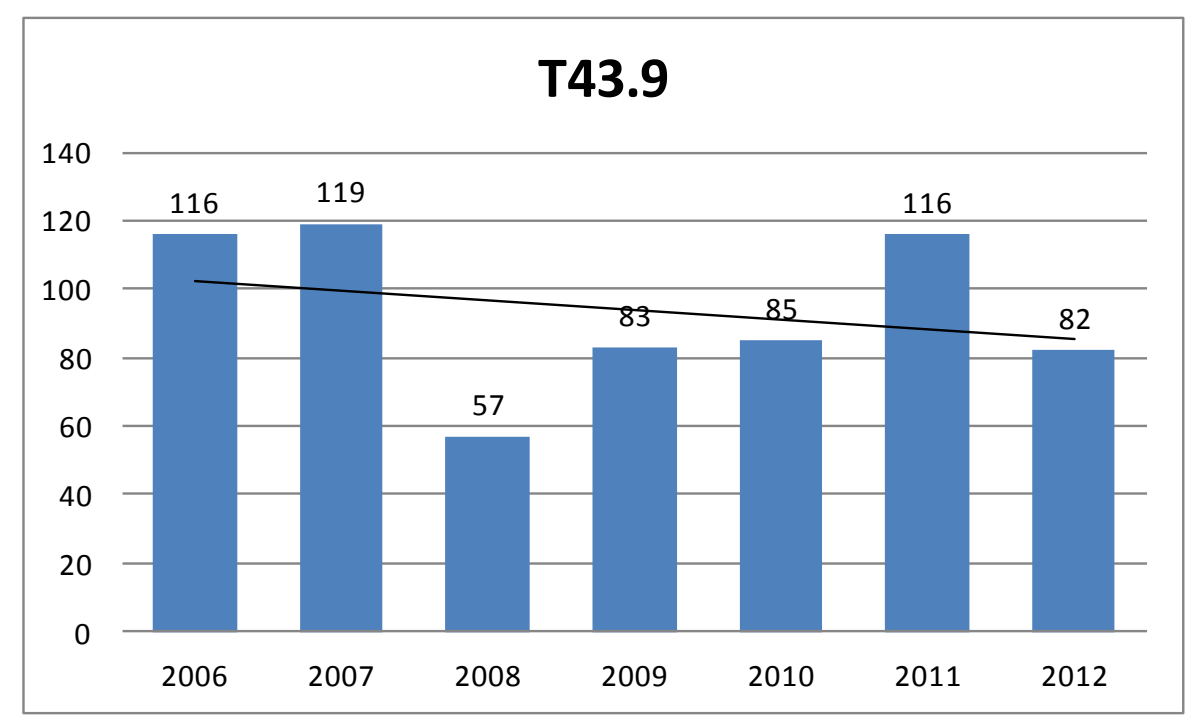

Figure10. Yearly amounts of admissions to hospitals in the Lower Silesia region of Poland in the years 20062012 due to poisoning by unspecified psychotropic drug (T43.9 according to ICD-10); source: data made available by courtesy of the NFZ.

\section{Conclusion}

The study revealed that in the Lower Silesia region of Poland in the years 2006-2012 the most commonly reported psychotropic drugs causing intoxications demanding hospitalization were antidepressants - especially tricyclic, tetracyclic and unspecified, which is the most important information for the differential diagnosis made by toxicologists as well as intensive care and anesthesiology specialists. There was significant increase in the amount of admissions to hospitals due to poisoning by psychotropic drugs reported without any further active substance specification, as well as due to intoxications caused specifically by: antidepressants other than tricyclic, tetracyclic and monoamine-oxidase-inhibitors; and neuroleptics. In contrast, there was a significant decrease in hospitalizations in the years 2006-2012 due to poisonings by monoamine-oxidase - inhibitor antidepressants; phenothiazine antipsychotics and neuroleptics; and psychotropic drugs other than antidepressants, antipsychotics, antineuroleptics and psychostimulants. In case of some drugs - like psychostimulants with abuse potential with the exception of cocaine - there amount of cases was 
alternating strongly from year to year. Those findings shall be interpreted in context of the shift in medical treatment strategies - from classic drugs into their newly developed alternatives - and the resultant availability of those groups of drugs to the general population.

The fact that in all analyzed years there was still significant amount of cases reported as poisoning by unspecified psychotropic drug, or more often as intoxication by such a drug without any further specification, confirms the still existing difficulties in establishing proper and full diagnosis in intoxications victims - despite the rapid progress in analytic chemistry techniques in the last decades.

\section{ACKNOWLEDGMENTS}

The authors thank the NFZ for allowing them the access to the publication-relevant data.

\section{REFERENCES}

[1] Bickel M., Acute and chronic toxicity of psychotropic drugs, Schweiz Arch Neurol Psychiatr, 1986, Vol 137, Issue 5, PP 106-109

[2] Zubiaur O, Salazar J, Azkunga B, Mintegi S, Therapeutic psychotropic drugs: Most common cause of unintentional poisoning in children, An Pediatr, 2015, Vol 83, Issue 4, PP 244-247 DOI: http://dx.doi.org/10.1016/j.anpede.2015.08.005

[3] Gjelsvik B, Heyerdahl F, Lunn D, Hawton K, Change in Access to Prescribed Medication following an Episode of Deliberate Self-Poisoning: A Multilevel Approach. PLoS ONE, 2014, Vol 9, Issue 5: e98086. DOI: http://dx.doi.org/10.1371/journal.pone.0098086

[4] Skegg K, Skegg D, Richards S, Incidence of self poisoning in patients prescribed psychotropic drugs, British Medical Journal, 1983, Vol 286, No 6468, PP 841-843 http:// www.jstor. org/ stable/29510106 [accessed: 30.07.2016]

[5] Tanaka N, Kinoshita H, Nishiguchi M, Jamal M, Kumihashi M, Takagashi M, Nishio H, Ameno K, An autopsy case of multiple psychotropic drug poisoning, Soud Lek, 2011, Vol 56, Issue 3, PP 38-39

[6] Kinoshita H, Nishiguchi M, Kasuda S, Ouchi H, Minami T, Matsui K, Yamamura T, Motomura H, Ohtsu N, Yoshida S, Adachi N, Aoki Y, Nagasaki Y, Ameno K, Hishida S, An autopsy case of poisoning with ethanol and psychotropic drugs, Soud Lek, 2008, Vol 53, Issue 2, PP 16-17

[7] Moens G, Loysch M, Hoggokoesomo S, Voorde H, Recent trends in methods of suicide, Acta Psychiatrica Scandinavica, 1989, Vol 79, Issue 3, PP 207-215 DOI: http://dx.doi.org /10. 111 1/ j.1600-0447.1989.tb10246.x

[8] Konoshita H, Naoko T, Ayaka T, Mostofa J, Asuka I, Shoji K, Kinhiko T, Shuji M, Kiyoshi A, Toxicological evaluation of psychotropic drug overdose in forensic practice, Journal of Drug Addiction, Education and Eradication, 2015, Vol 11, No 3/4 https://www.questia.com/ library/journa1/1P3-3970793611/toxicological-evaluation-of-psychotropic-drug-overdose [accessed: 30.07.2016]

[9] Corcoran P, Heavey B, Griffin E, Perry I, Arensman E, Psychotropic medication involved in intentional drug overdose: implications for treatment, Neuropsychiatry, 2013, Vol 3, Issue 3, PP 285-293 DOI: http://dx.doi.org/10.2217/NPY.13.23

[10] Drobnik J, Odonicz-Czarnecki G, Suslo R, Important to emergency medicine, medical intensive care and anesthesiology trends in hospital admissions due to poisonings by antiepileptic, sedative-hypnotic and anti-Parkinsonism drugs (T42 ICD-10) in the Lower Silesia Region of Poland in the years 2006-2012, ARC J Anesthesiol, 2016, Vol 1, Issue 2, PP 19-25 DOI: http://dx.doi.org/10.20431/2455-9792.0102004

[11] Drobnik J, Suslo R, Trnka J, Steciwko A, Jadach R, Psychiatric disorders in Lower Silesia region in 2002-2007 - increasing problem in family doctors' practice, Family Medicine and Primary Care Review, Fam Med Prim Care Revm, 2009, Vol 11, Issue 3, PP 293-295 http://www.familymedreview.org/files/2009/pdf_032009/2_original_papers_245_397.pdf [accessed: 30.07.2016]

[12] Lu C, Zhang F, Lakoma M, Mdden J, Rusinak D, Penfold R, Simon G, Ahmedani B, Clarke G, Hunkeler E, Waitzfelder B, Owen-Smith A, Raebel M, Rossom R, Coleman K, Copeland L, 
Soumerai $\mathrm{S}$, Changes in antidepressant use by young people and suicidial behavior after FDA warnings and media coverage: quasi-experimental study, BMJ, 2014, 348:g3596 DOI: http://dx.doi.org/10.1136/bmj.g3596

[13] Trnka J, Suslo R, Drobnik J, Mastalerz-Migas A, Rules of handling medical recipes, Fam Med Prim Care Rev, 2008, Vol 10, Issue 3, PP 1122-1125 http://www.familymedreview .org/files/2008/pdf_032008/5_reviews_1068_1196.pdf [accessed: 30.07.2016]

[14] Imran M, Screning for unknown compounds in forensic toxicology, ARC J Forensic Science, 2016, Vol 1, Issue 1, PP 10-12 DOI: http://dx.doi.org/10.20431/2456-0049.0101002

[15] Drobnik J, Suslo R, Kurpas D, Trnka J.: Analysis of elderly people care system and their health needs in the Lower Silesia region; Fam Med Prim Care Rev , 2010, Vol 12, Issue 2; PP 165-167 http://www.familymedreview.org/files/2010/pdf_022010/2_original_papers_127_312.pdf [accessed: 30.07.2016]

[16] Central Statistical Office of Poland Information Portal http://stat.gov.pl/statystykaregionalna/rankingi-statystyczne/ludnosc-wedlug-wojewodztw/ [accessed: 30.07.2016] 